\title{
NOTAS ACERCA DA INVENÇÃO DO NEGRO NO BRASIL
}

Caue Gomes Flor ${ }^{1}$

Resumo: Desde o final dos anos 1980 os povos, tradições e culturas de origem africana têm ocupado o centro de um profundo debate epistemológico. A perspectiva pós-colonial, se não for a maior protagonista desse debate epistêmico, tem concentrado grande parte de suas preocupações na investigação dos modos pelos quais as tradições de pensamento ocidental conheceram e, sobretudo, representaram o Outro do ocidente (em nosso caso o Negro). Esse artigo busca realizar justamente essa tarefa desconstrutivista. Busca-se compreender como a antropologia, particularmente na figura de Gilberto Freyre, construiu o negro no Brasil como um objeto teórico autorizado e passou a proporcionar um vocabulário capaz de identifica-lo e representa-lo. Por meio das críticas de autores internos a própria antropologia e autores pós-coloniais, como Homi Bhabha, Stuart Hall e Franz Fanon acerca das representações ocidentais sobre o Negro, o artigo conclui que, não diferente de outros contextos colonizados, a formulações de Freyre e, grosso modo, a antropologia se desdobram e reproduzem as problemáticas relações epistemológicas que marcam a relação colonial.

Palavras chave: Gilberto Freyre, antropologia, representação, relação colonial, epistemologia

Abstract: Since the late 1980s peoples, traditions and cultures of African origin have occupied the center of a deep epistemological debate. The postcolonial perspective, if not the major protagonist of this epistemic debate, has concentrated much of its preoccupations in the investigation of the ways in which the traditions of Western thought knew and, above all, represented the Other of the West (in our case the Negro). This article seeks to accomplish precisely this deconstructive task. It seeks to understand how anthropology, particularly in the figure of Gilberto Freyre, constructed the black in Brazil as an authorized theoretical object and started to provide a vocabulary capable of identifying and representing it. Through criticism from internal authors to anthropology itself and postcolonial authors such as Homi Bhabha, Stuart Hall, and

1 Graduado (Bacharelado e Licenciatura) em Ciências Sociais pela Universidade Estadual Paulista (Unesp/Campus de Marília). Ênfase/experiência em Antropologia, com habilitação em Antropologia das Populações AfroBrasileiras.Mestre em Sociologia pelo Programa de Pós-graduação em Sociologia da Universidade Federal de São Carlos (Ufscar). Com ênfase em Sociologia. Em especial Sociologia das Relações Raciais. Atualmente Doutorando do Programa de Pós-Graduação em Ciências Sociais pela Universidade Estadual Paulista (Unesp/Campus de Marília) com Bolsa FAPESP. Tem experiência em Teorias da Diáspora Africana, Estudos Pós-Coloniais,Teoria Antropológica, Identidade Negra, Identificação e Etnicidade. 
Franz Fanon about Western representations of the Negro, the article concludes that, not deferring from other contexts colonized, to Freyre's formulations and, roughly speaking, anthropology unfold and reproduce the problematic epistemological relations that mark the colonial relationship.

Keywords: Gilberto Freyre, anthropology, representation, colonial relation, epistemology

\section{INTRODUÇÃO}

Não foi fácil acomodar-se à situação tão inesperada: a de existir de certo modo a "minha" Dona Sinhá. Situação fantástica, até, embora não se tratasse de fantasma de fora do mundo: só fora do tempo e a reclamar para si uma existência que tornava a minha idéia de uma Dona Sinhá fictícia uma idéia que precisava, pelo menos, ser revista. (FREYRE, 2000, p. 18).

A narrativa acima está inscrita na obra Dona Sinhá e o Filho Padre, na qual Gilberto Freyre (1900-1987) faz a sua estreia no universo ficcional, instituindo simultaneamente um gênero à parte: a seminovela que, segundo o autor, trata-se de uma “[...] novela de novo tipo. Não por lhe faltar parte de sua virtude, mas por se apresentar enriquecida em sua perspectiva” (FREYRE, 2000, p. 18).

O livro Dona Sinhá e o Filho Padre é uma ficção, segundo Freyre, metapsíquica que envolve dois personagens centrais: José Maria, com a imposição duvidosa de sua vocação religiosa, e sua mãe Dona Sinhá. O romance trata do curioso caso ocorrido com um narrador (desprovido de nome) jornalista, que almejava escrever uma estória ficcional entre um jovem estudante ordenado a virar padre devido a sua homossexualidade e a sua mãe preocupada com tal situação. Tal estória era supostamente imaginaria até o momento em que o narrador recebe, pelas mãos de um moleque chamado Amaro “[...] tão retintamente preto que parecia um pajem”, um bilhete de uma senhora que desejava tratar com ele “assunto de interesse mútuo” (FREYRE, 2000, p. 14).

Ao seguir para a casa da senhora, como solicitado, o narrador encontra a personagem antes fictícia : “[...] nem alta nem baixa de alvura quase nórdica, surge ao fundo do corredor escuro uma senhora franzina a quem não faltava vigor autoritário nem no porte nem na voz [...]” (FREYRE, 2000, p. 16). Era uma Dona Sinhá como tantas neste Brasil. Dona Sinhá o acusa: “O senhor está abusando do meu nome. Não se faz isso com uma senhora” (FREYRE, 2000, p. 13). A personagem, outrora fictícia, apenas presente na estória que havia apenas iniciado nas paginas do jornal interpela-o. Dona Sinhá, de fato, existia. O narrador perplexo por aquela situação fantástica sente-se humilhado, pois pretendia libertar-se do imperialismo da história sobre a literatura. Surpreendendoo por querer traí-la com a ficção, a História, que havia tomado a figura de uma Dona Sinhá, o interpela (FREYRE, 2000, p. 30). 


\begin{abstract}
Se a História agora se apresentava como uma Dona Sinhá e um José Maria iguais aos meus, eu tinha a certeza de ter precedido a Historia com a minha ficçãozinha. Talvez ninguém acreditasse nessa precedência. Mas a mim me bastaria o gosto esquisito, que experimentara, de inventor de uma história e de uns personagens que arrancara se não de um todo, em grande parte, de minha imaginação. Se a História, para afirmar-se senhora absoluta das minhas pobres letras, não me permitia traí-la de público uma só vez, devia eu ter paciência; e resignar-me. (FREYRE, 2000, p. 30-31).
\end{abstract}

Nos pequenos trechos acima, ainda no início da narrativa descrita, em Dona Sinhá e o Filho Padre, ficção e história se confundem e criam um tempo, um tempo romântico, um seu roteiro sentimental. Cruzam-se espaço e tempo, passado e presente, ausência e presença, o branco e o negro. O escravo negro, a mulher e o menino são personagens da escritura freyriana, colocados como anti-heróis face ao patriarca, maior figura de autoridade e regulação do mundo colonial brasileiro, o grande herói civilizador (BASTOS, 2006). É no interior desse tempo mítico, desprovido de data, tipicamente moderno (BHABHA, 2013; ANDERSON, 2009) que as personagens acima inscritas foram, no processo de formação social, a garantia de uma harmonia resultante do hibridismo cultural as responsáveis pela adaptação não conflituosa dos diferentes aspectos das culturas portuguesas e africana (BASTOS, 2006, p. 14). Precisamente, o mito da Nação, o mito da democracia racial.

Casa Grande \& Senzala, escrita em 1933, é sem duvida a grande obra de Gilberto Freyre. Reconhecido pela literatura especializada como mito fundante da Nação, o texto tem desempenhado, desde sua publicação, um papel central nas discussões que compõe o pensamento social brasileiro. As avaliações em torno da sua obra e pensamento também são muitas e diversas. Entre os recentes trabalhos que recentemente ofereceram uma minuciosa análise acerca do pensamento de Freyre, trajetória e constituição intelectual, destacam-se, por exemplo, ambos trabalhos correlacionados da historiadora Maria Lucia Pallares-Burke, o primeiro, intitulado Gilberto Freyre: um vitoriano no trópicos (2005) e O triunfo do fracasso: Rüdiger Bilden, o amigo esquecido de Gilberto Freyre (2012).

Ante a complexidade e extensão da obra do autor relatadas em tais análises e da especial atenção dispensadas ao texto de 1933 e a Sobrando e Mucambos (2006[1936]), optamos, entretanto, em iniciar a análise que pretendemos desenvolver a partir de Dona Sinhá e o Filho Padre (2000). Ao se constituir como um romance, uma obra literária a principio no sentido restrito do termo, tal texto converge, num primeiro plano, para o cerne de nosso argumento, a saber: as formulações de Gilberto Freyre se comportam como uma forma de orientalismo ou discurso colonial, que foi e tem sido eficiente em não só produzir um conjunto de conhecimentos normativos sobre o povos, tradições e culturas de origem africana, como também oferecer um vocabulário autorizado para 
descrevê-los e representá-los no interior de quadro epistemológico que tem origem na relação colonial. Nesse sentido, os inventando enquanto objeto de conhecimento.

Num segundo plano, o texto Dona Sinhá e o Filho Padre dialoga com a proposta metodológica deste artigo. Isto é, o Negro e/ou os povos e tradições de origem africana têm estado, ao menos desde meados anos 1950, no centro de um profundo debate epistemológico na teoria social. Genealogicamente falando, os trabalhos de Frantz Fanon (1952[2008]), Aimé Césaire (1955[1972]), Cheik Anta Diop (1955), os Congressos Pan-Africanos (Decreane, 1962) e as lutas de libertação nacional no continente africano marcam a emergência desse debate no mundo ocidental. Na década de 1980, autores Stuart Hall, Homi Bhabha, Paul Gilroy e Gayatri Spivak, para citar alguns nomes, fizeram convergir em diferentes graus e sentidos, posições pós-estruturalistas, pósmodernas e anti-colonias. Num reenquadramento teórico-metodológico, que veio a ser denominado de pós-colonial, rejeitaram-se os esquemas ontológicos e epistemológicos do mundo moderno/colonial, fazendo avançar a agenda dos anos 1950 e 1960 a partir de um lugar evidentemente especifico.

Muito dessa proposta teórica e dessa agenda política reside, vale salientar, no trabalho e pensamento do martinicana Franzt Fanon. O oximoro Fanon, que tem sido apropriado e (re)lido a partir de diferentes lugares e perspectivas, os chamados Fanon Studies e/ou Fanonismos (GATES JR, 1991; HALL, 1996; HENRY, 2000; GORDON, 2015, FAUSTINO, 2015), desempenhou um papel fundamental para esses autores em diversos aspectos das suas formulações, com especial relevância para a crítica da identidade e o trato especifico da categoria racialização.

Foi sob esse termos que optamos em adentrar as escrituras freyrianas, a partir do premiado texto de Elide Rugai Bastos As criaturas de Prometeu: Gilberto Freyre e a formação da sociedade brasileira (2006). Ao abordar o escravo negro, a mulher, o menino e o amarelinho como personagens da escritura freyriana colocados como anti-heróis face ao patriarca, o grande herói civilizador, Bastos discute as formulações do autor como um modo de narrativa que, como veremos, sustenta sob as suas linhas, intencionalmente ou não, um conjunto de práticas de representação da diferença características dos discursos coloniais.

Nesse sentido, tendo em vista as inúmeras leituras, releituras, exaltações e acusações já realizadas sobre as teorizações e desdobramentos da obra de Gilberto Freyre, realizaremos não uma leitura, mas, por meio de leitores de Gilberto Freyre, especialmente, Bastos (2006), Hofbauer (2006), Correa (2013[1988]) e o próprio Freyre (2000, 2003, 2006), refletiremos sobre a forma como autor equalizou a relação entre raça e cultura em sua obra. Através de Fanon (2008; 1970), 
Said (1990), Hall (2010) e, sobretudo, Bhabha (2013) realizaremos nossa reflexão.

A começar por Fanon, nota-se que:

\begin{abstract}
A reflexão sobre o valor normativo de certas culturas, decretados unilateralmente, merece que lhe prestemos atenção. Um dos paradoxos que mais encontramos é o efeito de ricochete de definições egocentristas, sociocentristas. Em primeiro lugar, afirma-se a existência de grupos humanos sem cultura; depois a existência de culturas hierarquizadas; por fim, a noção de relatividade cultural. Da negação global passa-se ao reconhecimento singular especifico. É precisamente esta história esquartejada e sangrenta que nos falta esboçar ao nível da antropologia cultural (FANON,1970, p. 35)
\end{abstract}

Trata-se de um aviso e uma sugestão de se observar a forma que, em uma sociedade moderna colonial a relação entre racismo e cultura é encerrada. Assim, é a partir desse lugar que vamos direcionar o nosso olhar para essa relação central em Freyre entre raça e cultura, de modo a observá-la ao nível da antropologia cultural.

Para a realização dessa tarefa, vamos articular a nossa reflexão, a princípio com o próprio Fanon (1970), descrevendo um pouco mais minuciosamente como o autor pensa a relação entre racismo e cultura. Posteriormente, recorreremos a Bhabha (2013), uma vez que as suas elaborações estão em estreito diálogo com o pensamento de Fanon, especialmente com o texto de 1956 (FANON, 1970).

A tese de Fanon (1970) quanto a relação entre racismo e cultura postula a ideia de que o racismo não é mais que um elemento entre outros num conjunto mais vasto de opressão sistematizada de um povo. O racismo não seria um fenômeno estático, pois, por um lado, tem a capacidade de se moldar conforme o contexto histórico específico, por outro lado, transforma-se no interior de uma mesma sociedade. Para o autor, é possível observar uma transformação e, de certo modo, refinamento na forma como o racismo se manifesta e produz os seus efeitos. De forma geral, o racismo científico converteu-se após a “Segunda Guerra Mundial” em Racismo cultural, pautado pela negação das formas de existir dos povos colonizados.

O autor argumenta que essa forma de racismo, o cultural, não mais se concentra necessariamente em determinado genótipo ou fenótipo. Ou seja, “[...] a expropriação, a razia, o assassínio objetivo, desdobram-se numa pilhagem dos esquemas culturais, ou pelo menos condicionam essa pilhagem [...]” (FANON, 1970, p. 37). Prossegue, então, através de uma doutrina da hierarquia cultural, que não é mais do que uma modalidade de hierarquização sistematizada e prosseguida de maneira implacável com o objetivo de destruição dos sistemas de referência dos nativos, ou seja, suas culturas. 
Esta cultura, outrora viva e aberta ao futuro, fecha-se (grifo nosso), aprisionada no estatuto colonial, estrangulada pela carga da opressão. Presente e simultaneamente mumificada, depõe contra seus membros. Com efeito, define-os sem apelo (grifo nosso). A mumificação cultural leva a mumificação do pensamento individual. [...]. Como se fosse possível que um homem evoluísse de modo diferente que não no quadro de uma cultura que o reconhece e que ele decide assumir. (FANON, 1970, p. 38).

Isto quer dizer que em contextos nos quais se prevalece essa forma de racismo, o procedimento de fixação ontológica do ser negro (o outro) permanece por meio de um processo mais sofisticado de fixação/racialização, agora ao nível da cultura. Dessa forma, é garantido o valor normativo e hierárquico de certas culturas sobre as outras. É sobre esses processos e práticas representacionais que Bhabha (2013) se concentra em evidenciar como que a cultura opera enquanto aparato de poder e regulação ${ }^{1}$.

Nesse sentido, passamos a trabalhar com Bhabha (2013) visando problematizar e demonstrar que determinados aspectos das elaborações de Freyre remontam esse sofisticado processo de fixação cultural. Isto é, podendo ser apresentado enquanto discurso colonial. Segundo o autor, a principal característica do discurso colonial é a sua dependência do conceito de “fixidez” na construção da alteridade. Essa problemática é explorada pelo autor no respectivo capítulo constitutivo do seu livro O local da cultura - A outra questão: o estereótipo, a discriminação e o discurso do colonialismo (BHABHA, 2013, p. 117). Bhabha (2013) elabora uma categoria ampla cujo objetivo é explicitar a forma como a alteridade é representada, preocupação sintetizada sob a categoria estereótipo. Para o autor, a categoria é constituída por outras três, a saber ambivalência, essencialismo sincrônico e fetiche.

Assim, nosso percurso seguiu através das três categorias constitutivas do estereótipo do discurso colonial, correlacionando-as com um conjunto de problematizações sobre aspectos específicos da obra de Freyre. Por meio do próprio Gilberto Freyre (2000, 2003 e 2006) de leitores de Freyre, especialmente Bastos (2006), Hofbauer (2006), iniciaremos a próxima seção com a noção de ambivalência.

\section{AMBIVALÊNCIA}

A fixidez, como signo da diferença cultural/histórica/racial no discurso do colonialismo, é um modo de representação paradoxal: conota rigidez e ordem imutável como também desordem, degeneração e repetição demoníaca. Do mesmo modo, o estereótipo, que é a sua principal estratégia discursiva, é uma forma de conhecimento e identificação (grifo nosso) 
que vacila entre o que esta sempre “no lugar”, já conhecido, e algo que deve ser ansiosamente repetido... como se a duplicidade essencial do asiático ou a bestial liberdade sexual do africano, que não precisam de prova, não pudessem ser provados jamais no discurso. (BHABHA, 2013, p. 117).

O conceito de ambivalência é um dos efeitos da negação do jogo da diferença que por sua vez caracteriza a racialização. É dessa negação que emerge um duplo: o branco e o negro. É dessa duplicidade que o autor remete à sua noção de ambivalência. Trata-se precisamente do processo de fixidez imutável e repetição ansiosa que denota o aspecto central do estereótipo, que constrói o discurso colonial. É o poder da ambivalência que dá ao estereótipo colonial sua validade: “[...] garante a sua repetibilidade em conjunturas históricas e discursivas mutantes.”

Nesse sentido, o primordial é reconhecer o estereótipo como um modo ambivalente de conhecimento que desloca a noção de identificações, como positivas ou negativas, para a compreensão de processos de subjetivação tornados possíveis e plausíveis. Segundo o autor, se, a princípio, não tomarmos a imagem estereotipada a partir de uma normatividade política, se é possível produzir um deslocamento e lidar com sua eficácia. Isto é, com o repertório de posições de poder e resistência, dominação e dependência, que constrói o sujeito da identificação colonial, tanto colonizador como colonizado (BHABHA, 2013, p. 118).

A ressalva de Bhabha quanto à improdutividade analítica de partir de uma suposta normatividade política quanto ao estereótipo, apresenta-se como um bom ponto de partida para as nossas reflexões. Isso é importante na medida em que uma das problemáticas centrais do debate da questão do negro no Brasil é justamente a crítica à mestiçagem como marca da identidade nacional e o empecilho ideológico na construção de uma identidade negra consciente.

Ao deslocarmos a nossa atenção para os processos de subjetivação, como sugerido por Bhabha, que se tornaram possíveis a partir do estereótipo, não se trata mais, partindo dessa perspectiva, de desconstruir o discurso colonial denunciando as suas repressões ideológicas (elas estão postas já há muito no debate brasileiro). Trata-se, então, de compreender a produtividade do poder colonial. Dito de outro modo, como o discurso colonial de Freyre produz o colonizador e o colonizado. Supomos que esse processo nos traz outras problemáticas.

O discurso colonial é uma prática de representação que produz tanto o colonizado quanto o colonizador. Assim como diz Fanon (2008, p. 26-27), “[...] avançaremos lentamente, pois existem dois campos: o branco e negro. Tenazmente questionaremos as duas metafísicas e veremos que elas são frequentemente muito destrutivas. [...]. O branco está fechado na sua brancura. E negro na sua negrura.” Todavia, nesse momento, gostaríamos de adentrar o campo branco, o campo do 
colonizador.

\begin{abstract}
O fato social dessa divergência entre os sexos - um mais militante, outro mais estável evidentemente se prende ao físico da mulher-mãe: mais sedentário; também à variabilidade, ou tendência para divergir do normal, tendência, ao que parece a alguns estudiosos do assunto como Ellis, maior no homem do que na mulher, do mesmo modo que parece a alguns antropólogos, maior na raça branca do que na negra. A mulher se apresenta, nas suas tendências conservadoras e docemente conformistas e coletivistas, o sexo que corresponderia à raça negra - a raça "lady-like”, como já disse o sociólogo norte-americano Park; o homem, pelo seu individualismo, pendor para divergir da normalidade, quer no sentido do genial, quer no do subnormal, pela capacidade e gosto de diferenciação, o sexo que corresponderia à raça branca (FREYRE, 2006, p. 218).
\end{abstract}

Segundo Bhabha (2013, p. 119), a produção do sujeito colonial no interior do discurso do estereótipo exige a articulação de duas formas de diferença: racial e sexual. Para o autor, essa articulação é fundamental na construção de práticas de hierarquização, relação que a citação acima apresenta de forma axiomática. São relações nas quais a inferioridade do "negro" africano escravizado é associada de forma naturalizada à suposta subserviência feminina, correspondendo a determinadas aptidões e características comportamentais. Nessa análise de Freyre inscrita em Sobrados e Mocambos as diferenças raciais e sexuais são vistas como duas formas de diferenciação que são irredutíveis uma a outra, mas percebidas e articuladas de modo interseccionado.

Bastos (2006, p. 53) ao destacar a importância das quatro personagens nacionais da escrita freyriana (criaturas de prometeu - o escravo negro, a mulher, o menino e o amarelinho) demonstra que o autor as posiciona em sua obra como o oposto da lógica da dominação. Sendo assim, antagonismos, figuras a margem da lógica histórica, que só são perceptíveis ao intelectual não pelo método histórico convencional, mas por uma nova forma de compreender o social: a empatia. Nesse caso, penso que seria profícuo deslocar a ideia de antagonismo para a noção de ambivalência que permeia a constituição das personagens.

O escravo negro "o maior e mais plástico colaborador do branco” na construção da nova civilização [...]. "Verdadeiro dono da terra”, dominando a cozinha, a vida sexual, as profissões técnicas, a música, alterando a língua, amante e confidente. Letrado, “felizes dos meninos que aprenderam a ler e a escrever com professores negros, doces e bons”. $\mathrm{O}$ verdadeiro colonizador do Brasil. A mulher, submissa, “criada em ambiente rigorosamente patriarca”, "vivendo sob a mais dura tirania dos pais - depois substituída pala tirania dos maridos"; só chamando o marido de "senhor". O menino, em casa judiando das negrinhas e dos moleques, "mas na sociedade dos mais velhos judiado era ele” conservando-se calado, ar seráfico, tomando a benção dos mais velhos, dizendo "senhor meu pai" e "senhora minha mãe”. Os três aliados; os escravos defensores “dos filhos contra os senhores pais”, das mulheres de quinze anos contra os "senhores maridos" de quarenta e cinquenta, de sessenta e setenta. $\mathrm{O}$ amarelinho, menino mimado, franzino, acalentado pelas mucamas, pelas mães e madrinhas, sem gosto pela lides do engenho, sem pulso para o mando de senhor, saindo de casa para estudar nos seminários ou nas escola das capitais do Brasil e da Europa, voltando imbuído de novas ideias, pronto para lugar contra a dominação (BASTOS, 2006, p, 53-54). 
Segundo a autora (Bastos, 2006, p. 54), Freyre sugere que, o único hábil a compreendê-los é o intelectual capaz de desdobrar-se em cada uma dessas figuras, saindo de sua personalidade para tomar as dos outros. Ao tomá-los como personagens, Freyre busca demonstrar que estão aparentemente fora da lógica da história e, ao torná-los personagens, o autor também nos autoriza a tomar a sua construção como narrativa. Nessa narrativa da nação brasileira, todas as personagens são postas ante o herói colonizador: o senhor, o português. Todos carregam em relação ao senhor, consigo e, entre si, tensões marcadas por violência/cordialidade, presença/ausência, prazer/desprazer, inscritas em relações ambivalentes, determinadas tanto pela dimensão sexual quanto pela raça. A descrição realizada por Freyre (2000) do Filho Padre de Dona Sinhá é reveladora dessa característica do estereótipo no interior do discurso colonial.

\begin{abstract}
Traços muito delicados. Um aspecto mais de moço que de rapaz: talvez um toque angélico no seu todo difícil de ser interpretado em puros termos biológicos. E outra vez devo dizer que esse já era meu filho de Dona Sinhá antes de ser o da fotografia que vi na casa de São João do Ribamar, enfeitada de flores: esse padrezinho que morreu antes de ser ordenado, mais moça que rapaz no seu aspecto angélico pela sua vida religiosa e sincera; e que, abandonado à vida mundana, teria talvez se esboçado num maricas de modos melifluamente afeminados, de olhos voltados para rapazes fortes com desejo de mulher lúbrica por homens ostensivamente machos (FREYRE, 2000, p. 32).
\end{abstract}

A ambivalência em função do estereótipo do discurso colonial encontra sua forma mais bem acabada na sociedade brasileira sublinhada pelo patriarcalismo, que articula poder racial e, ao mesmo tempo, um conjunto de práticas de regulação oriundas do sexismo. Uma forma de poder e regulação característica e constituinte da sociedade brasileira. Produto da colonização portuguesa, a família e, sobretudo, o patriarcado civilizador, veiculado à personagem do homem português, seria o núcleo das relações sociais brasileiras. Fora o patriarcalismo o grande responsável pela acomodação e conciliação de possíveis conflitos em nossa sociedade.

Seguindo esse raciocínio, o patriarcalismo enquanto aparato de poder colonial, tende a se apoiar no reconhecimento e repúdio de diferenças raciais/culturais/históricas. Enquanto forma de conhecimento por meio da qual se exerce, através de uma economia mista entre raça e sexo, poder, regulação e vigilância, o patriarcalismo se transforma em um modo de governabilidade que ao delimitar os subalternos (as criaturas de prometeu), apropria, dirige e domina várias esferas de atividade. E, enquanto produtos do poder e do discurso colonial, as personagens de Freyre estão agregadas na narrativa da nação, inscritas em um sistema de representação que os torna inteiramente apreensíveis, forma de representação que estruturalmente se aproxima do realismo 
(BHABHA, 2013, p. 124).

\section{O TRANSITO INCOMPLETO}

Embora não se reconheça essencialmente como um antropólogo, sociólogo ou romancista, Gilberto Freyre se afirmava caudatário direto das elaborações do antropólogo alemão Frantz Boas, radicado nos Estados Unidos (1858-1942). A escola antropológica Culturalista Norte Americana, como ficaram conhecidas as concepções boasianas, promove um movimento central em antropologia, qual seja, a desconexão entre raça e cultura, dissociando a suposta estreita relação entre essas duas dimensões, separando o que pertenceria ao biológico da esfera da cultura. Foi a desnaturalização dessa relação o fundamento que garantiu os veementes ataques ao conceito de raça, especialmente na década dos anos 1950.

No entanto, como o trabalho dos antropólogos Marisa Corrêa (2013[1998]) e Andreas Horfbauer (2006) demonstram que tal desnaturalização e transito teórico-metodológico, na ciência da cultura no Brasil, no caso de Freyre em particular, não se realizou, ao menos não completamente. Na primeira edição de Casa Grande \& Senzala (1933) Gilberto Freyre declara que a diferenciação conceitual boasiana entre raça e cultura, “[...] entre os efeitos de relações puramente genéticas e os de influências sociais, de herança cultural e do meio [...]” são as concepções teóricas que orientam suas elaborações. "Neste critério de diferenciação fundamental entre raça e cultura se assenta o plano desse ensaio” (HOFBAUER, 2006, p. 245). Nessa ordem de ideias, o pensamento de Freyre se apresenta como uma ruptura relativa ao racismo primitivo, substrato das políticas de branqueamento da população brasileira, característica transição do século XIX para o XX. A partir da obra do autor caminhamos da esfera da biologia para a esfera da cultura.

Segundo Hofbauer, a obra de Freyre revela que, embora reclamasse sua orientação boasiana, por vezes recorria a noções de "raças superiores" e "raças inferiores", ou ainda, "raças atrasadas". Em Sobrados e Mocambos (1936), o autor apresenta, inclusive, uma definição de raça que não faz jus às ideias de seu professor em Columbia, seja por falta de precisão cientifica, seja por não ter se convencido das palavras de Boas a respeito da raça:

Freyre (1951 [1936], III, p. 1080-1081) afirma - não sem antes rechaçar explicitamente qualquer noção de determinismo (étnico, geográfico, econômico) - que a raça, o meio físico e as técnicas de produção devem ser entendidos como "forças que condicionam o desenvolvimento humano, sem determinarem de modo rígido e uniforme”. E adianta: “A raça dará as predisposições; condicionará as especializações de cultura humana. Mas essas especializações desenvolve-as o ambiente total - ambiente social mais do que puramente física ou à classe a que pertença o indivíduo.” (HOFBAUER, 2006, p. 245, grifo 
do autor).

Hofbauer prossegue argumentando que é possível encontrar em toda a obra de Freyre expressões como "povos atrasados” e “culturas adiantadas”, persistindo, portanto, a transposição das ideias ligadas ao discurso racial evolucionista do século XIX. Embora, para o autor, Freyre também não explique os critérios para a classificação entre as culturas mais ou menos adiantadas ou atrasadas. Todavia, seu texto não hesita em apostar que tais classificações hierárquicas foram orientadas pela ideia clássica de progresso (tratado como um "fenômeno neutro", desvinculados a contextos históricos e a valores culturais específicos) (Hofbauer, 2006, p. 246).

Hofbauer (2006) demonstra que Freyre, por vezes, escorrega nos usos da(s) cultura(s), ora aproximando-se das orientações boasianas, ora estreitando relação com os discursos raciais do século XIX que concebia cultura no singular, como expressão da “civilização”. No limite, ao diferenciar o Brasil do que ocorrera nos Estados Unidos, afirma que a formação do povo brasileiro foi beneficiada pelo melhor da cultura negra da África (Hofbauer, 2006, p. 246, grifo nosso).

Partindo desde os últimos pontos destacados por Hofbauer (2006), o que nos chama atenção é a assertiva de que diferentemente do que aconteceu nos Estados Unidos, o Brasil recebera e se beneficiara do que há de melhor da cultura negra da África. Afirma que em determinados aspectos, especialmente, na arte e técnica, o negro superava o ameríndio e até o português devido à complexidade dos estoques culturais mais adiantados oriundos de África que vieram para Brasil (Bastos, 2006, p. 128).

Ao olharmos para essa questão a partir da produtividade do estereótipo do discurso colonial como produtor do sujeito colonial (colonizado e colonizador) a preocupação torna-se a compreensão da representação e, mais, a interpretação da diferença, nesse caso racial/cultural nas elaborações de Freyre. Quanto à representação e interpretação da diferença no interior do discurso colonial, certamente a crítica de Said (1990, p. 81) em Orientalismo é reveladora.

Filosoficamente, portanto, o tipo de linguagem, pensamento e visão, que eu venho
chamando de orientalismo de modo muito geral, é uma forma de realismo radical; que é o
habito de lidar com questões, objetos, qualidades e regiões consideradas orientais, vai
dignar, nomear, apontar, fixar, aquilo sobre o que está falando ou pensando através de uma
palavra ou expressão, que é vista como algo que conquistou ou simplesmente é a realidade.
O tempo verbal que empregam é o eterno atemporal; transmitem uma impressão de
repetição e força. Para quase todas as funções é quase sempre suficiente usar a simples
cópula é. O FETICHE E A NARRATIVA PEDAGÓGICA DA NAÇÃo

Para problematizarmos esse aspecto é necessário adentrar a problemática por meio de uma 
forma de estereótipo mais profunda: o fetiche ou estereótipo enquanto fetiche. Esse é território dos sonhos, imagens, fantasias, mitos, obsessões e requisitos (BHABHA, 2013, p. 125). Para que possamos compreender o fetiche do estereótipo partiremos do papel designado ao "escravo negro na vida sexual e de família do brasileiro”

\begin{abstract}
Da escrava ou sinhama que nos embalou. Que nos deu de mamar. Que nos deu de comer, ela mesma amolengando na mão o bolão de comida. Da negra velha que nos contou as primeiras histórias de bicho e de mal-assombrado. Da mulata que nos tirou o primeiro bicho-de-pé de uma coceira tão boa. De que nos iniciou no amor físico e que nos transmitiu, no ranger da cama-de-vento, a primeira completa de homem. Do moleque que foi nosso companheiro no brinquedo. (FREYRE, 2003, p. 367).
\end{abstract}

Segundo Bhabha (2013, p. 125) reconhecer o estereótipo enquanto prática de representação é de certa forma nos aproximarmos das elaborações de Said (1990) quanto ao orientalismo. Said (1990) estabelece uma oposição entre duas cenas: o colonialismo latente que diz respeito ao inconsciente, escritos imaginativos e ideias essenciais; e o colonialismo manifesto, diacrônico, determinado histórico e discursivamente. O que lhe permite a correlação como sistema congruente de representação que é unificado através de uma intenção político-ideológica, que em suas palavras, assegura a Europa avançar segura e não meteoricamente sobre o oriente.

Segundo Bhabha, essas duas cenas estão colocadas em uma estrutura binária de divisão/correlação, o que mina a noção poder/conhecimento de Foucault, que reside na recusa de oposições entre essência/aparência, ideologia/ciência (BHABHA, 2013, p. 125-126). O argumento é que os sujeitos (colonizador e colonizado) estão sempre colocados de forma desproporcional nas relações de poder. Torna-se difícil, então, conceber enunciações históricas do discurso colonial sem que elas estejam sobredeterminadas, estrategicamente elaboradas ou deslocadas pela cena inconsciente do orientalismo latente (Bhabha, 2013, p. 126). Em outras palavras, o estereótipo enquanto fetiche articula o histórico e a fantasia (o fetiche como cena do desejo).

É o fetiche que garante a excitação/hesitação contraditória de Freyre ao exaltar a contribuição das culturas negras africanas para construção da brasilidade e a volta repentina e repetitiva dos estereótipos de inferioridade racial do XIX. Enquanto forma contraditória de reconhecimento e repúdio da diferença racial/histórica/cultural, na sua necessária articulação de duas formas de poder, regulação e vigilância (raça-sexo) (Bhabha, 2013), o patriarcalismo sintetiza essa prática de representação. 
que só gozam com negra. De rapaz de importante família rural de Pernambuco conta a tradição que foi impossível aos pais promoverem-lhe o casamento com primas ou outras moças brancas de famílias igualmente ilustres. Só queria saber de molecas. Outro caso, referiu-nos Raoul Dunlop de um jovem de conhecida família escravocrata do Sul: este para excitar-se diante da noiva branca precisou, nas primeiras noites de casado, de levar para a alcova a camisa úmida de suor, impregnada de bodum, da escrava negra sua amante. (FREYRE, 2003, p. 368).

Por fim, a isso se soma a forma que Freyre articula o tempo, em sua narrativa, da formação da nação brasileira. Temporalidade denominada por Bastos (2006) como roteiro sentimental. Suas andanças e descrições pelas ruas e praças parecem sugerir que "a identidade do lugar resiste ao fluxo do tempo”. Ao descrever o panorama transmite, como que pairando no ar, o espírito de homens pretéritos. Ao mesmo tempo, aparecem aos nossos olhos casas e assombrações: o presente é eivado de passado (Bastos, 2006, p. 48). Descreve o Recife como o masculino viril, o macho e também o lugar da política. A Olinda feminina, ao mesmo tempo, ascética e erótica, com a religiosidade das igrejas. Macho e fêmea se completam sem conflito. Uma única cidade. Mas nem tudo é tão simples. No verão existiria uma face feminina. Na mulher também viveria um homem (Bastos, 2006, p. 48-49).

Recife/Olinda, como Gilberto a(s) vê: cosmopolita e provinciana; democrática e autoritária; popular e aristocrática; republicana e monárquica; libertária e escravocrata; liberal e conservadora. Eis a marca freyriana que simbolizada na descrição do espaço: há em todas as coisas o aparente e o escondido: em todos os fenômenos, os contrários se encontram, convivem pacificamente. O que vale para o lugar se estende para as relações sociais: branco e negro; senhor e escravo; homem e mulher; adulto e menino. Essa dualidade aparentemente excludente encontrará sempre o equilíbrio: antagonismo em equilíbrio. (BASTOS, 2006, p. 49).

O que nos faz retornar as primeiras linhas dessa reflexão pois, mais do que uma descrição geográfica, o roteiro sentimental é um tempo, no fundo um espaço-tempo donde as coisas permanecem; como elas são. Tempo em que há a conciliação, é o tempo da narrativa da nação. Tempo de seu romance, em que ficção e história coincidem. Em que, assim como já averiguamos, fantasia (desejo) e história se amalgamam em uma linearidade temporal homogênea.

Era de fato uma Sinhá autêntica: muito senhora e muito brasileira; e nada cômica, nem no sentido em que ela dava a palavra cômica, nem ao outro. Gritou a Amaro e o moleque não tardou de aparecer, com o seu sorriso bom. Estava limpando as gaiolas dos passarinhos. Dona Sinhá com a voz de Wanderley, filha de senhor de engenho - com certeza de Sarinhaém, pensei eu -, disse ao molecote que trouxesse dois cafés bem quentinhos. [...]. Temi, porém, café forte. Disse-lhe então que recomendasse que para mim viesse café fraco. Ela compreendeu e disse a Amaro, na voz sempre autoritária, mas ao mesmo tempo muito doce na expressão dos olhos 
e de rosto inteiro, que para mim trouxesse vinho do Porto. E baixinho, quase segredou ao bom negro: "daquela garrafa que está em cima da cômoda dos santos.” (FREYRE, 2000, p. 21-22).

O trecho acima ilustra de forma exemplar o tempo da narrativa da nação (roteiro sentimental), bem como explicita a sua principal e complexa estratégia de representação e interpelação cultural, que funciona em nome da nação moderna, mais precisamente, em nome de sua equação: um território, uma língua, um povo e uma cultura formam uma nação. Trata-se de uma temporalidade dupla de representação: o que foi, era e sempre será o mesmo. Essa estratégia tem por objetivo produzir uma temporalidade homogênea cuja potencialidade é normatizar aquele termo suplementar que também constitui e denuncia os limites da equação da nação-moderna, qual seja: a diferença racial/cultural/histórica. Essa temporalidade ao mesmo tempo escreve e narra a modernidade da nação como o evento e cotidiano e o advento do memorável (BHABHA, 2013, p. 231).

Segundo o autor, tratar as formações nacionais modernas a partir da noção de narrativa é uma forma de dar ênfase à dimensão temporal dessas entidades políticas. É essa temporalidade homogênea, vazia, atemporal, que possibilita aos historiadores da nacionalidade - transfixados no evento e nas origens, aos teóricos políticos possuídos pelas totalidades "modernas” da nação e valerem de fragmentos culturais, símbolos e monumentos. Os fixando nesse espaço-tempo homogêneo, que encontra sua imagem mais bem acabada nas linguagens diversas da crítica literária, que buscam retratar a enorme força da nação nas exposições da vida cotidiana, nos detalhes reveladores que emergem como metáforas e metonímias da vida nacional. Esses historicistas fascinados pela nação se furtam da pergunta essencial, da representação da nação como processo temporal (BHABHA, 2013, p. 232).

Nesse sentido, não é apenas o roteiro sentimental que atravessa toda a obra de Freyre, mas também a forma pela qual o autor se relaciona com tempo, nesse caso a tradição é central. Segundo Bastos, ao se deparar com as profundas mudanças que transcorrem na virada do século XIX para o $\mathrm{XX}$, Freyre constata que, embora os tempos tenham mudado, os costumes permanecem. De que os elementos do passado continuaram a se desenvolver. Isso o faz um daqueles intelectuais que buscam compreensão das forças sociais que tem raiz no passado, com efeito, sendo, por vezes, considerado um romântico, conservador, regionalista e tradicionalista. Em outros termos, Gilberto Freyre quer mostrar como a ordem pretérita é constitutiva da ordem presente através das relações sociais, das atitudes e de modos de pensar, explícitos, submersos ou latentes que teriam sobrevivido 
a mudança (BASTOS, 2006, p. 46).

Mas como falar de tradições em um país tão novo como o Brasil? É por meio da invenção das tradições, no sentido que Hobsbawm atribuiu ao termo, que o autor escreve/narra os seus textos dedicados à formação da nação - Casa Grande \& Senzala, Sobrados e Mocambos e Ordem e Progresso. Narrativas escritas desde um espaço-tempo homogêneo, atemporal, mítico, mas, sobretudo, da acomodação e conciliação dos conflitos. É por isso que o método utilizado para a reconstrução da história é a empatia. Isso explica o fato da história em Gilberto Freyre não ser datada (BASTOS, 2006, p. 47). Assim, em Dona Sinhá e o Filho Padre, Freyre descreve com grande empatia, a partir de sua posição transfixada no tempo, em que ficção e história (entre o latente e o manifesto) se misturam à paisagem cotidiana da brasilidade através de suas criaturas. Quando ao tempo Freyre narra:

Haveria um tempo artisticamente fictício que fugisse ao domínio histórico mas fosse perseguido pelo histórico até que os dois tempos se tornarem, pelo menos em alguns casos, um tempo só? Haveria uma verdade aparentemente inventada - a da ficção - parecendo independente da história, mas de fato verdade histórica, a qual solta no ar - no ar psíquico - a sensibilidade ou a imaginação de algum novelista mais concentrado na sua procura de assunto ou personagem, a apreendesse por um processo metapsíquico ainda desconhecido? (FREYRE, 2000, p. 31).

Quanto ao roteiro sentimental, do tempo homogêneo e atemporal, em que a nação é narrada como evento do cotidiano e advento do memorável:

Comecei a dizer para mim mesmo: "São José não falha: continua a ter a coragem de ser não só um espaço como um tempo a parte dos outros espaços e dos outros tempos recifenses”. Recifenses só não: brasileiros. Isto mesmo: brasileiros. (FREYRE, 2000, p.16).

Essa temporalidade dupla da nação, essa ambivalência, garante que o tempo seja fixado de tal forma que a nação sempre foi, era e será representada como uma unidade cultural holística, estática e coesa. Para tanto, Bhabha vai destacar, por um lado, o caráter pedagógico nacionalista da narrativa, enquanto prática representacional que se baseia no preestabelecido ou na origem histórica constituída no passado; por outro também consiste em um processo de significação que deve obliterar qualquer presença anterior, dessa forma estabelecendo para si o status de contemporânea, no qual a vida nacional é readmitida e reiterada (BHABHA, 2013, p. 237). Parafraseando o próprio Freyre (2000), a nação é escrita/narrada na paisagem de um moleque chamado Amaro, tão retintamente preto que parecia um pajem de José de Alencar, sempre solícito com um sorriso bom; e 
em uma Dona Sinhá que se apresenta docemente familiar no porte, na figura, na voz, causam a estranha e permanente impressão de déjà vu.

\section{CONCLUSÃO: RACISMO E REPRESENTAÇÃO}

Aqui podemos começar a concluir a nossa reflexão. Fanon ao salientar a mudança de uma forma de racismo mais rudimentar e arcaico, para uma mais sofisticada, denota que essa transformação está intimamente associada ao processo de complexificação dos meios de produção. A evolução das relações econômicas, a perfeição dos meios de produção provoca fatalmente a camuflagem das técnicas de exploração do homem, logo das formas de racismo (FANON, 1970, p. 39). Dito de outro modo, é a transição de sociedades tradicionais para sociedades modernas o elemento que deflagra esse deslocamento. Essa premissa fanoniana é um ponto de inflexão que ao mesmo tempo me possibilita retomar um dos temas centrais, segundo Bastos (2006), da obra de Freyre.

Segundo Bastos, um dos aspectos principais da obra de Freyre é a sua preocupação com a transição: a passagem do trabalho escravo ao trabalho livre, da monarquia à república, do campo à cidade. E que, todavia, esses processos profundos de transformação não levam a uma ruptura no seio da sociedade, justamente, por causa da articulação entre patriarcalismo, etnias/culturas e trópico. Dessa articulação emerge a principal característica da nação brasileira: a conciliação (BASTOS, 2006, p. 12). Sendo o patriarcalismo, a pedra angular dessa conciliação, que mesmo em decadência (processo descrito em Sobrados e Mocambos) garantiu a interpenetração de valores sociais de caráter diversificado; através dele operou uma síntese não conflituosa que impediu rupturas. Sob essa conciliação tipicamente brasileira, na mudança alteram-se as formas e o acessório, mas o substantivo permaneceu. A transformação não se processou de modo linear; tem a conformação de um labirinto, seu trabalho busca a reconstrução desses caminhos sinuosos (BASTOS, 2006, p. 13-14).

De fato, nesse processo de transição, partindo desde a inflexão fanoniana, a forma e o acessório mudaram, mas o substantivo permaneceu. A complexa síntese cultural elaborada por Freyre que se sintetiza sob as linhas do termo mestiçagem e ampliada sob o lusotropicalismo e que encontra forma mais refinada na democracia racial, é operada enquanto aparato epistemológico na interpretação do Brasil. Tal aparato, inegavelmente, produziu um conjunto de deslocamentos no trato da diferença racial que por sua vez ressoaram decisivamente na formação da sociedade brasileira. 
No entanto, partindo não de uma leitura, mas das problematizações desenvolvidas ao longo de nossa reflexão, com base em Fanon $(2008,1970)$ e Bhabha (2013) é possível afirmar que, muito embora Freyre desloque o arcabouço utilizado para a compreensão e interpretação da sociedade brasileira, o substantivo continua colaborando para a reificação de uma sociedade de caráter colonial, ou melhor dizendo, pós-colonial. Dessas problematizações, podemos desdobrar que as elaborações de Freyre podem ser compreendidas, e esse é um aspecto já presente como prerrogativa inicial, como uma forma de discurso colonial. Enquanto tal, esse foi o intuito da argumentação, articular um conjunto de características, no fundo estratégias de representação que, intencionalmente ou não, corroboram para uma intricada relação entre contexto colonial, racialização e cultura, sobretudo entre os dois últimos. Isto se dá por meio do estereótipo e de suas três categorias constitutivas - ambivalência, essencialismo sincrônico e fetiche -, um refinado processo de fixação cultural (racialização).

A profunda radicalidade desse processo é sublinhada por Bhabha (2013) ao denunciar que o estereótipo é uma forma de conhecimento e identificação que vacila entre o que está sempre "no lugar”, já conhecido, e algo que deve ser ansiosamente repetido; de reconhecimento e repúdio de diferenças raciais/culturais/históricas. Enquanto prática colonial de representação, o discurso colonial e/ou as elaborações de Freyre dão acesso a identidades marcadas pela fantasia e desejo da origem e que, por consequência, definem-se como um conhecimento estereotipado.

O discurso racista estereotípico, em seu momento colonial inscreve uma forma de governamentalidade que se baseia em uma cisão produtiva em sua constituição do saber e exercício do poder. Algumas de suas práticas reconhecem a diferença de raça, cultura e história como sendo elaborada por saberes estereotípicos, teorias raciais, experiência colonial administrativa, institucionaliza uma série de ideologias políticas e culturais [...]. Ao "conhecer" (grifo nosso) a população nativa nesses termos, formas discriminatórias e autoritárias de controle político são consideradas apropriadas. A população colonizada é tomada como causa e efeito do sistema presa no círculo de interpretação. (BHABHA 2013, p. 141-142).

De forma geral, as ideias de Freyre, que aparecem como uma outra perspectiva relativa ao racismo biológico do final do século XIX, são uma forma muito mais complexa e sofisticada de racismo cultural (FANON, 1970).

As sínteses desse processo - a mestiçagem e a democracia racial enquanto narrativa da nação - remontam aquilo que Hall (2010, p. 423) denomina de regimes racializados de representação. Segundo a taxonomia do autor, é possível identificar três desses regimes: o primeiro, o contato que ocorreu no século XVI entre os comerciantes europeus e os reinos africanos; o segundo, a colonização europeia da África e da Ásia e o controle do território colonial; e o terceiro, 
diz respeito à migração do terceiro mundo para a Europa e América do Norte após o fim da $2^{\circ}$ Guerra Mundial. Em cada um desses momentos, houve um conjunto de práticas e figuras destinadas a representar a diferença, nesse caso racial, na cultura popular do ocidente.

Embora as construções de Freyre extrapolem as experiências analisadas por Hall (2010), em especial as duas últimas classificações, a noção de regime racializado de representação tende a ser profícua, não apenas porque o autor também destaca o estereótipo como principal prática significante debruçada sobre a diferença no ocidente, mas, por outras duas premissas subjacentes à sua assertiva. A primeira é a de que a despeito da mudança do regime de representação, este permanece racializado; e a segunda indicando que cada transição implica na mudança das relações de representação. Nessa ordem de ideias, há uma transição entre regimes e relações de representação inaugurada nas concepções de Freyre, porém, o substantivo permanece.

Trabalhando com Hofbauer (2006), torna-se mais profunda a análise, ao correlacionarmos sua tese a de Bhabha (2013), Hall (2010) e Fanon (2008): na medida em o estereótipo implica em processos de subjetivação/identificação inscritos em um regime de representação racializado, redundando em formas de conhecimento estereotípico, que oscila entre o que está sempre "no lugar”, já conhecido, e algo que deve ser ansiosamente repetido. Os infindáveis ideais de branqueamento enunciados por Hofbauer (2006) são, nesse sentido, mascaramentos metafóricos da negrura que deve ser então ocultada, garantindo ao estereótipo a sua fixidez fantasmática - sempre as mesmas histórias sobre a animalidade do negro. Ou em nosso caso: o melhor da cultura africana, o sorriso bom de Amaro, ou a mulata que nos iniciou no amor carnal, a brasilidade conciliadora e mestiça. Todas essas infindáveis reformulações são traduzidas de forma sintética no título fanoniano Pele negra, máscaras brancas.

O que nossa reflexão nos permite concluir: a mestiçagem e a democracia racial têm a capacidade não apenas de se posicionar como um obstáculo ideológico a construção de uma identidade negra em detrimento de uma identidade nacional (Munanga, 1999). A democracia racial, enquanto mito, perpetua e (re)produz as desigualdades entre brancos e negros no Brasil (Guimarães, 2002). Ao compreender a mestiçagem e a democracia racial como uma forma complexa e sofisticada de racismo cultural, se é possível extrair mais uma consequência de seus desdobramentos.

Ambas, reinscrevem, reificam e reencenam o drama e as cenas da relação colonial (pós-colonial) cotidianamente. Nas formas de conhecimento (reconhecimento e repúdio da diferença racial/cultural/histórica), nas possibilidades de subjetivação/identificação (estereotipadas e 
fetichizadas), nas formas de governalidade, regulação, normatização e vigilância na política. A mestiçagem e a democracia racial, em seus efeitos, contribuem para a formação do que Hall (1980) denomina de sociedades racialmente estruturadas em dominância. A última letra é de Fanon, pois sempre nos depararmos com as seguintes palavras: a relação/diferença colonial está sendo (re)posta: “Preto sujo!” Ou simplesmente: “Olhe, um preto!” (Fanon, 2008, p. 103).

\section{REFERÊNCIAS}

ANDERSON, B. Comunidades Imaginadas. Companhia da Letras, 2008[1983].

BASTOS, E. R. As criaturas de Prometeu: Gilberto Freyre e a formação da sociedade brasileira. São Paulo: GLOBAL, 2006.

BHABHA, H. O entrelugar das culturas. In: BHABHA, H. O bazar global e o clube dos cavaleiros ingleses. Rio de Janeiro: Rocco, 2011.

BHABHA, H. O local da cultura. Belo Horizonte: Ed. UFMG, 2013 [1998].

CÉSAIRE, AIMÉ. Discurso sobre o colonialismo. LIVRARIA DE SA COSTA EDITORA, 1978[1955].

CORREA, M. As ilusões da liberdade: a escola de Nina Rodrigues e a Antropologia no Brasil. Fundação Osvaldo Cruz, 2013[1998].

DIOP, C, A. The African origin of civilization myth or reality. Lawrence Hill \& Co., 1974[1955].

DECRAENE, P. O Pan-Africanismo. São Paulo: Difusão europeia do livro, 1962.

FANON, F. Racismo e cultural. In: FANON, F. Em defesa da revolução Africana. Lisboa: Livraria Sá da Costa. 1970. Original de 1956.

FANON, F. Os condenados da terra. Juiz de fora: Ed. UFJF, 2005.

FANON, F. Pele negra, máscaras brancas. Salvador: EDUFBA, 2008[1952].

FAUSTINO, D, M. "Porque Fanon? Por que agora? Frantz Fanon e os fanonismos no Brasil. Tese de Doutorado - Universidade Federal de São Carlos, 2015.

FREYRE, G. Casa-Grande \& Senzala: formação família brasileira sobre o regime patriarcal. São Paulo: Global, 2003[1933]. 
FREYRE, G. Sobrados e mucambos: decadência do patriarcado e desenvolvimento do urbano. São Paulo: Global, 2006 [1936].

FREYRE, G. Dona Sinhá e o Filho Padre. Editora EDIOURO, 2000[1964].

GATES, H, L, Jr. Critical Fanonism; In: Critical Inquiry, Vol. 17, No. 3, 1991, p. 457-470.

GORDON, L. What Fanon sad. Fordham University Press, 2015.

GUIMARÃES, A. S. A. Classes, raças e democracia. São Paulo: Ed. 34, 2002.

HALL, S. Race, articulation and societies structured in dominance; In: Sociological theories: race and colonialism. Unesco, 1980.

HALL, S. The after-life of Frantz: why Fanon? Why now? Why Black Skin, White Masks?, In: READ, L. (Ed) The fact of Blackness: Frantz Fanon and the visual representation, Institute of Contemporary Art, Seattle, Bay Press, 1996, p. 186 - 204.

HALL, S. Sin garantias: trayectorias y problemáticas em estúdios culturales. Evión Editores. 2010 [1989].

HENRY, P. Caliban's Reason: Introducing Afro-Caribbean Philosophy, New York, Routledge, 2000.

HOFBAUER, A. Uma história de branqueamento ou o negro em questão. São Paulo: Ed. UNESP, 2006.

MUNANGA, K. Rediscutindo a mestiçagem no Brasil: identidade nacional versus identidade negra. Petrópolis: Editora Vozes, 1999.

PALLARES-BURKE, M, L. Gilbeto Fryre: um vitoriano no trópicos. Editora Unesp, 2005.

PALLARES-BURKE, M, L. O triunfo do fracasso: Rüdiger Bilden, o amigo esquecido de Gilberto Freyre. Editora Unesp, 2012. 